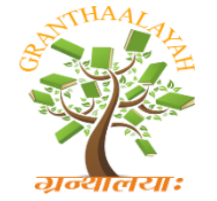

INTERNATIONAL JOURNAL OF RESEARCH GRANTHAALAYAH A knowledge Repository

RAST - 17

\title{
A SHORT REVIEW GLUTEN FREE FOODS
}

\author{
Chandralekha ${ }^{1}$, Amar Sankar ${ }^{2}$, R.C. Chandni ${ }^{3}$, A. V. Raghu ${ }^{4}$ \\ 1, 2, 3,4 Department of Food Technology, Centre for Emerging Technology, Jain University, 562
} 112 , India

DOI: https://doi.org/10.29121/granthaalayah.v5.i4RAST.2017.3294

\begin{abstract}
The present article review about gluten its health effects and development of gluten free foods. Celiac disease is the main disease caused due to gluten indigestibility. Wheat is the main constituent in the production of bakery products and gluten is the main protein in the wheat. It has been well recognized that the only effective treatment for celiac disease is a persistent lifelong avoidance of food products containing wheat and similar cereal grains. At present, there is still substantial demand for gluten-free products that meet consumer needs in terms of sensory quality, conveniences and price values. Wheat (Gluten) is the main component for quality of the bakery products. Gluten free foods are produced by the gluten free sources. The gluten free sources selected should have same characteristics as gluten and should have same effect as gluten on quality of the bread.
\end{abstract}

Keywords: Gluten; Quality; Celiac Disease; Bakery Products.

Cite This Article: Chandralekha, Amar Sankar, R.C. Chandni, and A. V. Raghu. (2017). "A SHORT REVIEW GLUTEN FREE FOODS.” International Journal of Research Granthaalayah, 5(4) RAST, 1-6. https://doi.org/10.29121/granthaalayah.v5.i4RAST.2017.3294.

\section{Introduction}

A gluten-free diet is a diet that excludes foods containing gluten. Gluten is a protein complex found wheat, barley, rye and triticale. A gluten-free diet is the only medically accepted treatment for celiac disease. Being gluten intolerant can often mean a person may also be wheat intolerant as well as suffer from the related inflammatory skin condition dermatitis herpetiformis. There are a smaller minority of people who suffer from wheat intolerance alone and are tolerant to gluten. Despite unknown benefits for the general population, and evidence to suggest adverse effects, a significant demand has developed for gluten-free food in the United States. The term glutenfree generally is used to indicate a supposedly harmless level of gluten rather than a complete absence. The exact level at which gluten is harmless for people with celiac disease are uncertain and controversial. A 2008 systematic review tentatively concluded that consumption of less than $10 \mathrm{mg}$ of gluten per day for celiac disease patients is unlikely to cause histological abnormalities, 
[Raghu et. al., Vol.5 (Iss.4: RAST), April, 2017]

ICV (Index Copernicus Value) 2015: 71.21

Recent Advances in Science \& Technology
ISSN- 2350-0530(O), ISSN- 2394-3629(P)

IF: 4.321 (CosmosImpactFactor), 2.532 (I2OR)

InfoBase Index IBI Factor 3.86

although it noted that few reliable studies had been conducted. International Codex Alimentarius standard allows for 20 parts per million of gluten in so-called "gluten-free" foods. Gluten-free food is normally seen as a diet for celiac disease, but people with a gluten allergy (an unrelated disease) should also avoid all other grain. Several grains and starch sources are considered acceptable for a gluten-free diet. The most frequently used are corn, potatoes, rice, and tapioca (derived from cassava). Other grains and starch sources generally considered suitable for gluten free diets

Include arrowroot, millet, montina, lupin, quinoa,sorghum (jowar), taro, teff, chia seed, and yam. Sometimes various types of bean, soybean, and nut flours are used in gluten-free products to add protein and dietary fiber.

\section{Processing of Gluten Free Foods}

The common ingredients in GF pasta are flour and/or starch from corn, rice, potato (or other tubers), with the addition of protein, gums, and emulsifiers which may partially act as substitutes for gluten. The diversity of Gluten Free raw materials help to increase the quantity and the quality of products for celiacs. Formulating GF pasta requires, firstly, a thorough knowledge of the component properties of GF flours and starches. Then, appropriate additives may be selected to promote a cohesive mass in the product. After initial trials the formulation are fixed as toasted Soy flour, Channa Flour, Sorghum flour and WPC with Xanthan gum, Guar Gum, and Hydroxy propyl methyl cellulose (HPMC) as additives in different combination per $100 \mathrm{~g}$ of formulation. Control pasta is prepared with only Triticum durum flour $(100 \mathrm{~g})$. Details of the pasta formulation are provided in Table. Flour is mixed in Hobart mixer (model N-50, Ontario, Canada) using low speed of $0.46 \mathrm{~g}$ with optimal $30-40 \mathrm{~mL}$ of water/100 $\mathrm{g}$ of flour and mixed for 7e10 min. Mixed samples are extruded using La Moniferrino (Model Dolly, Asti, Italy) pasta extruder. The samples are dried at $70^{\circ} \mathrm{C}$ for $3 \mathrm{~h}$ in Sakar Drier (Shirsat Electronics, Mumbai) and packed in polypropylene covers for further use.

Table 1: Formulations for gluten free pasta processing

\begin{tabular}{|l|l|l|l|l|l|l|l|l|}
\hline \multicolumn{1}{|c|}{ Flours } & \multicolumn{1}{|c|}{ IX } & \multicolumn{1}{|c|}{ IIH } & IIIGG & IVXHG & \multicolumn{1}{|c|}{ VC } & \multicolumn{1}{c|}{ VI } & NC1 & NC2 \\
\hline Toasted soy flour $(\mathrm{g})$ & 29.85 & 29.85 & 29.85 & 29.77 & 30.00 & 31.08 & 29.62 & 39.50 \\
\hline Toasted channa flour $(\mathrm{g})$ & 34.82 & 34.82 & 34.82 & 34.74 & 35.00 & 36.29 & 34.60 & 24.70 \\
\hline Toasted sorghum flour $(\mathrm{g})$ & 29.85 & 29.85 & 29.85 & 29.77 & 30.00 & 31.08 & 29.62 & 29.62 \\
\hline Whey protein concentrate $(\mathrm{g})$ & 4.98 & 4.98 & 4.98 & 4.97 & 5.00 & - & 4.92 & 4.94 \\
\hline Xanthan gum (g) & 0.50 & - & - & 0.25 & - & 1.55 & 0.50 & 0.50 \\
\hline Guar gum (g) & - & - & 0.50 & 0.25 & - & - & 0.24 & 0.24 \\
\hline HPMC (g) & - & 0.50 & - & 0.25 & - & - & 0.50 & 0.50 \\
\hline
\end{tabular}

IX- Gluten Free (GF) pasta with Xanthan gum, IIH - GF pasta with HPMC (Hydrox propyl methylcellulose), IIIGG - GF pasta with Guar Gum, IVXHG - GF pasta with Xanthan gum, HPMC and Guar Gum, VC - GF pasta without any additive, VI - GF pasta without WPC , NC1 - New combination 1 and NC2 - New combination 2 
[Raghu et. al., Vol.5 (Iss.4: RAST), April, 2017]

ICV (Index Copernicus Value) 2015: 71.21

Recent Advances in Science \& Technology
ISSN- 2350-0530(O), ISSN- 2394-3629(P)

IF: 4.321 (CosmosImpactFactor), 2.532 (I2OR)

InfoBase Index IBI Factor 3.86

\section{Gluten Free Bread Making Procedure}

Gluten-free bread formulation based on $100 \mathrm{~g}$ jasmine rice flour consisted of $1.5 \%$ yeast, $9 \%$ sugar, $1.5 \%$ salt, $10 \%$ shortening is used in this study. The amount of water addition is $80 \%$ (flour weight basis, fwb), which is determined in the preliminary experiment to produce the best bread quality. When a pregelatinised tapioca starch is substituted for the rice flour, three formulations are investigated using three levels of substitutions at 10, 20 and $30 \% \mathrm{w} / \mathrm{w}$; the formulations according to the level of substitution are here called PG10, PG20 and PG30, respectively. For bread making, sugar and salt are dissolved in deionised water. This is subsequently mixed with shortening and other dry ingredients using a three speed dough mixer equipped with a dough hook (Kittiwattana model KV-05, Thailand) at a medium speed for 10 min. After complete mixing, dough is rested in the mixing bowl for another $10 \mathrm{~min}$. Next, about $90 \mathrm{~g}$ of dough is placed into a mould and proofed in a convection oven (Toshiba Model ERD300C, Toshiba, Thailand) at $40 \mathrm{C}$ for $40 \mathrm{~min}$. Following the fermentation, the samples are baked at $200 \mathrm{C}$ for $20 \mathrm{~min}$. Four bread samples are prepared for each formulation. For comparison purpose, control bread from wheat flour is also prepared using a similar formulation as the rice bread but a lower water addition of $60 \%$ fwb is used (Cauvain \& Young, 2006).

\section{Gluten-Free Bread Production}

The following ingredients are used for bread production: buckwheat flour (Doves Farm Foods Ltd, UK), oat flour, quinoa flour, sorghum flour, teff flour, 70 wheat flour, yeast, sugar and salt. Breads are produced as previously described by Hager et al. (2012a) using 100\% flour, 2\% salt, $2 \%$ sugar and $3 \%$ dry-yeast (based on flour, BF). Optimal water addition level (WL) for glutenfree flours is determined through preliminary baking trials (buckwheat: 85\% BF, Oat, Quinoa, Sorghum and Teff bread: 95\% BF) and with the farinograph method (AACC 2000) for wheat flour $(63 \% \mathrm{BF})$. Bulk fermentation of wheat dough is carried out for $15 \mathrm{~min}$ at $30^{\circ} \mathrm{C}$ and $85 \%$ relative humidity $(\mathrm{RH})$. The gluten-free bread batters and the wheat dough are proofed in tins for 30 and $75 \mathrm{~min}$, respectively $\left(30^{\circ} \mathrm{C}, 85 \% \mathrm{RH}\right)$ and baked in a deck-oven (gluten-free breads for 45 min at $190^{\circ} \mathrm{C}$; wheat bread for $30 \mathrm{~min}$ at $220^{\circ} \mathrm{C}$ top and $235^{\circ} \mathrm{C}$ bottom heat). Breads are cooled for two hours at room temperature and frozen $\left(-18^{\circ} \mathrm{C}\right)$ until analysis. Three batch replicas are prepared. Commercial bread (soft white loaf, ingredients: water, corn starch, tapioca starch, potato starch, dried egg white, white rice flour, buckwheat flour, rice bran, thickening agent: xanthan gum; yeast; cellulose; sourdough: fermented quinoa and rice flour); psyllium; salt; rapeseed oil; pea protein; agar agar; potassium sorbate; thickening agent; guar gum; hydroxypropyl methylcellulose; flour treatment agent: ascorbic acid, raising agent: sodium bicarbonate) is analysed as a gluten-free reference.

\section{Gluten- Free Layer Cake}

A single-bowl mixing procedure is used for making yellow layer cakes. The basic recipe and the fiber enriched formulations replacing up to $20 \mathrm{~g} / 100 \mathrm{~g}$ rice flour are detailed in Table 1 . All ingredients are mixed during $1 \mathrm{~min}$ at speed 4, and $9 \mathrm{~min}$ at speed 6 using a Kitchen-Aid Professional mixer e KPM5. $180 \mathrm{~g}$ of cake batter are placed into rectangular (109 $\mathrm{mm}-159 \mathrm{~mm})$, metallic, oil coated pans (430 mL of capacity), and are baked in an electric oven ST-02 for 30 $\mathrm{min}$ at $190^{\circ} \mathrm{C}$. After baking, the cakes are removed from the pans, left at room temperature for 1 
[Raghu et. al., Vol.5 (Iss.4: RAST), April, 2017]

ICV (Index Copernicus Value) 2015: 71.21

Recent Advances in Science \& Technology
ISSN- 2350-0530(O), ISSN- 2394-3629(P)

IF: 4.321 (CosmosImpactFactor), 2.532 (I2OR)

InfoBase Index IBI Factor 3.86

$\mathrm{h}$ to cool down, and put into plastic pouches to prevent drying. Two different sets for each cake recipe are made in different days. Four cakes from the same batter are used for physical measurements that are carried out one day after baking. One cake from each set is freeze dried for further determination of the in vitro enzymatic hydrolysis of starch

Table 2: Formulations of Gluten free layer cake (g/100 g flour or flour-fiber blends)

\begin{tabular}{|l|l|l|l|l|l|}
\hline Forumalation & Control & Oat-Guar gum & Oat -Inulin & Oat & Inulin \\
\hline Rice Flour & 100 & 80 & 80 & 80 & 80 \\
\hline Oat fiber 600 & 0 & 15 & 15 & 20 & 0 \\
\hline Inulin & 0 & 0 & 5 & 0 & 20 \\
\hline Guar gum & 0 & 5 & 0 & 0 & 0 \\
\hline Milk & 75 & 75 & 75 & 75 & 75 \\
\hline Eggs & 62.5 & 62.5 & 62.5 & 62.5 & 62.5 \\
\hline Sunflower oil & 37.5 & 37.5 & 37.5 & 37.5 & 37.5 \\
\hline Sugar & 112.5 & 112.5 & 112.5 & 112.5 & 112.5 \\
\hline Baking powder & 3.75 & 3.75 & 3.75 & 3.75 & 3.75 \\
\hline Total (g) & 391.25 & 391.25 & 391.25 & 391.25 & 391.25 \\
\hline
\end{tabular}

Gluten-free layer cakes enriched in soluble and insoluble fibers of acceptable quality can be obtained, without affecting significantly the specific volume and only slightly the crumb texture. Oat fiber blend with inulin or guar gum is proposed for increasing the fiber content of gluten-free cakes. Rice flour replacement up to $20 \mathrm{~g} / 100 \mathrm{~g}$ by dietary fibers modifies the batter properties, the technological qualitative parameters (volume, texture) and nutritional composition of the cakes. Due to health benefits derived from the intake of fiber containing foods and the recommendation to still balance the consumption of soluble and insoluble fibers, the blend of oat inulin (insoluble-soluble fiber) showed advantages in front of the blend oat guar gum, pertaining nutrition and quality of enriched gluten-free layer cakes. Future studies will be undertaken for determining the sensory quality and consumer acceptance of enriched gluten-free cakes by organizing a consumer test with celiac patients.

\section{Gluten-Containing Ingredients and Questionable Products}

Gluten-containing grains, starches, and flours Barley, Bulgur, Cereal binding, Couscous, Durum, Einkorn, Emmer, Far rob, Graham flour, Kamut, Malt malt extract malt flavoring malt syrupc, Oats, oat bran, oat syrup, Rye, Semolina, Spelt, Triticale, Wheat, wheat bran, wheat germ, wheat starch

\section{Frequently over Looked Foods that often Contain Gluten}

Baked beans, Breading, Chocolate bars, Communion wafers, Croutons, Dry roasted nuts, Gravy, Icings and frostings, Imitation bacon bits, Imitation seafood, Licorice, Marinades, Meat loaf, Pastas ,Processed meats and poultry, Roux, Salad dressings, Sauces, Sausage products, Seasonings, Self-basting poultry, Soups, soup bases, broth, bouillon cubes, Soy sauce, Stuffing's, Thickeners. 


\section{Conclusion}

Celiac disease is common intestinal disorder which can be treated only through strict gluten free diet. Gluten is the main component of wheat and other cereal flours. The replacement of gluten in the foods leads to many major changes in the quality of the product. By using starches, gums and hydrocolloids problem of gluten replacement in foods can be overcome. Novel techniques as well as use of dietary fibres, other protein and starch sources and additives enhance the gluten free products in their nutritional values. These types of products are very useful people with gluten sensitivity to avoid severe conditions such as celiac disease.

\section{Acknowledgements}

We thank the Ministry of Food Processing and Industries, (MOFPI), Government of India for the award of Food Technology Centre, CET, Jain University.

\section{References}

[1] AACC. (2000). Approved methods of the AACC (10th ed.). St. Paul, MN, USA: American Association of Cereal Chemists.

[2] Akeson, W. R., \& Stahmann, M. A. (1964). A pepsin pancreatin digest index of protein quality evaluation. Journal of Nutrition, 83, 257.

[3] Alamprese, C., Caseraghi, E., \& Pagani, M. A. (2007). Development of gluten free fresh egg pasta analogues containing buckwheat. European Food Research and Technology, 225, 205e213.

[4] Arendt, K. K., O'Briend, C. M., Schober, T.J., Gormely, T. R., \& Gallagher, E. (2002).Development of gluten-free cereal products. Farm and Food, 12, 21-27.

[5] Chirdo, F. D., Anon, M. C., \& Fossti, C. A. (1995). Optimization of a competitive ELISA with polyclonal antibodies for quantification of prolamins in foods. Food and Agricultural Immunology, 7, 333-345

[6] Alvarez-Jubete, L., Arendt, E. K., \& Gallagher, E. (2010). Nutritive value of pseudocereals and their increasing use as functional gluten-free ingredients. Trends in Food Science and Technology, 21, 106-113.

[7] An, H. J., \& King, J. M. (2007). Thermal characteristics of ohmically heated rice starch and rice flours. Journal of Food Science, 72, C084-C088.

[8] Bhattacharya, K. R. (2004). Parboiling of rice. In E. T. Champagne (Ed.), Rice: Chemistry and technology (pp. 329e404). St. Paul: The American Association of Cereal Chemists.

[9] Adhikari, K., Dooley, L. M., Chambers, E., IV, \& Blumiratana, N. (2010). Sensory characteristics of commercial lactose-free milks manufactured in the United States. LWT e Food Science and Technology, 43, 113-118.

[10] Albenzio, M., Santillo, A., Caroprese, M., Braghieri, A., Sevi, A., \& Napolitano, F.(2013). Composition and sensory profiling of probiotic Scamorza ewe milk cheese. Journal of Dairy Science, 96, 2792-2800.

[11] Alvarez-Jubete, L., Auty, M., \& Arendt, E. K. (2010). Baking properties and microstructure of pseudocereal flours in gluten-free bread formulations. European Food Research and Technology, 230, 437-445.

[12] Amerine, M. A., Pangborn, R. M., \& Roessler, E. B. (1965). Principles of sensory evaluation of food. New York: Academic Press.

[13] Basman, A., Köksel, H., \& Ng, P. K. W. (2002). Effects of increasing levels of transglutaminase on the rheological properties and bread quality characteristics of two wheat flours. European Food Research and Technology, 215, 419-424. 
[14] Bourne, M. C. (1982). Principle of objective measurement. In Food texture and viscosity: Concept and measurement. New York: Academic press.

[15] Cauvain, S. P., \& Young, L. S. (2006). Baked products: Science technology and practice. UK: Blackwell Publishing.

[16] Crockett, R., Ie, P., \& Vodovotz, Y. (2011). How do xanthan and hydroxypropyl methylcellulose individually affect the physiochemical properties in a model gluten-free dough? Journal of Food Science, 76, E274-E282.

[17] AACC, I., 2000. Methods 44-15A, 54-21. In A.A.o.C. Chemists (Ed.), Approved Methods of the American Association of Cereal Chemists. St. Paul, MN.

[18] Alminger, M., Eklund-Jonsson, C., 2008. Whole-grain cereal products based on a high-fibre barley or oat genotype lower post-prandial glucose and insulin responses in healthy humans. European Journal of Nutrition 47, 294-300.

[19] Atkinson, F.S., Foster-Powell, K., Brand-Miller, J.C., 2008. International tables of glycemic index and glycemic load values: 2008. Diabetes Care 31, 2281-2283.

[20] Banchathanakij, R., Suphantharika, M., 2009. Effect of different beta-glucans on the gelatinisation and retrogradation of rice starch. Food Chemistry 114, 5-14.

*Corresponding author.

E-mail address: gsraghu2003@yahoo.co.in 